\title{
PROTAGONISMO ESTUDANTIL NA PROFISSIONALIZAÇÃO DOCENTE
}

\author{
Osmar Hélio Alves Araújo \\ Dayana Silva de Oliveira
}

\section{Resumo}

Neste texto, discutem-se desafios enfrentados na formação inicial dos professores, mais especificamente, para a permanência e o êxito dos estudantes em cursos de licenciatura, a partir da experiência do desenvolvimento do Projeto Profissão Docente (PPD) no Instituto Federal de Educação Ciência e Tecnologia do Ceará (IFCE), campus Tianguá. Na implantação do projeto, surgiram algumas questões básicas: quais condições, nos cursos de licenciatura em física e letras - português/inglês do referido campus, podem favorecer a profissionalização docente? Qual o papel das diversas disciplinas das licenciaturas na profissionalização docente? $\mathrm{O}$ referido artigo parte de um referencial teórico adotado a luz da temática formação docente, protagonismo estudantil e do empirismo vivenciado a partir do PPD. A experiência relatada permitiu saber que, em face de uma cultura acadêmica de vários desafios, faz-se necessário forjar uma cultura pedagógica fortemente associada à profissionalização docente, assim como as potencialidades da constituição de comunidades - discentes e docentes - para além do que já ocorre dentro da sala de aula.

Palavras-chave: protagonismo estudantil; disciplinas pedagógicas; formação docente.

\section{STUUDENT PROTAGONISM IN TEACHING PROFESSIONALIZATION}

\begin{abstract}
This text discusses the challenges faced in initial teacher training, more specifically concerning student permanence and success in undergraduate courses, based on the experience of developing the Profession Teacher Project (PPD, in Portuguese) at the Ceará Federal Institute of Education, Science and Technology (IFCE, in Portuguese), Tianguá campus. Some basic questions arose when implementing this project, such as: in the physics and languages - portuguese/english undergraduate courses offered at the IFCE Tianguá campus, which elements can enable the teaching professionalization? What is the role of different undergraduate courses in teaching professionalization? This text is based on a theoretical framework adopted in the light of the theme of teacher training, student roles and empiricism experienced from the PPD. The reported experience allowed us to know that, in the face of an academic culture of various challenges, it is necessary to forge a pedagogical culture strongly associated with teaching professionalism, as well as the potential of constituting communities - students and teachers - to go far beyond the classroom.
\end{abstract}

Keywords: student protagonism; pedagogical subjects; teacher training. 


\section{PROTAGONISMO ESTUDANTIL EN LA PROFESIONALIZACIÓN DOCENTE}

\section{Resumen}

En este texto se discuten los desafíos enfrentados en la formación inicial de los profesores, específicamente, para la permanencia y el éxito de los estudiantes en carreras de licenciatura, a partir de la experiencia del desarrollo del Proyecto Profesión Docente (PPD) en el Instituto Federal de Educação, Ciência e Tecnologia de Ceará (IFCE), Campus Tianguá. En la implantación de este proyecto surgieron algunos interrogantes básicos: ¿Cuáles condiciones, en las carreras de licenciatura en física y letras portugués/inglés del IFCE/campus Tianguá, pueden favorecer a la profesionalización docente? ¿Cuál es el papel de las distintas disciplinas de las carreras de grado en la profesionalización docente? Este artículo parte de un marco teórico adoptado a la luz de la temática de la formación docente, los roles de los estudiantes y el empirismo vivido desde el PPD. La experiencia relatada nos permitió saber que, ante una cultura académica de diversos desafíos, es necesario forjar una cultura pedagógica fuertemente asociada a la profesionalidad docente, así como al potencial de constituir comunidades - alumnos y docentes - más allá de lo ya desarrollado en las clases.

Palabras clave: protagonismo estudiantil; materias pedagógicas; formación docente.

\section{DESCORTINANDO AS PERSPECTIVAS EXPOSTAS NO TEXTO*}

A formação docente é um tema recorrente e apresenta-se de modo extensivo e intensivo na literatura especializada atual. Entretanto, é bem verdade que a preocupação com essa formação se tornou mais onipresente em face dos desafios e demandas eclodidas no século XXI, como a universalização do ensino médio e educação infantil, a elevação do atendimento na creche, a implantação de escolas de tempo integral, entre outros, cujas ações foram asseguradas no Plano Nacional de Educação (PNE 2014-2024). O itálico em preocupação visa destacar que, por um lado, não é possível renovar a formação dos professores, sobretudo no Brasil, se não houver valorização da profissão docente, que abarca, necessariamente, formação inicial e contínua, condições de trabalho, plano de carreira, piso nacional salarial profissional com tempo para planejamento e estudos. Por outro lado, visa destacar que não é possível pensar sobre a melhoria da educação brasileira partindo, tão somente, de uma espécie de preocupação com a qualificação docente.

Historicamente, a formação inicial dos professores, tida como um processo que marca a entrada na profissão docente e a partir do qual os estudantes constroem conhecimentos e desenvolvem competências inerentes à docência, constitui-se, ainda, um velho e sempre presente problema da formação para o magistério.

Um dos principais dilemas para quem opta pela docência refere-se ao (des)prestígio social e à valorização salarial da profissão e, a partir daí, nem sempre é fácil decidir o rumo profissional a tomar. Nesse quadro, inserem-se muitos estudantes dos cursos de licenciatura que vivem o dilema de manter sua opção pela docência ou mudar seu percurso profissional. É aí que surge um primeiro desafio: possibilitar aos estudantes a (re)descobrir caminhos, ainda que transitórios, de aproximação e identificação com a docência onde não haja somente a motivação profissional, mas também uma identidade profissional. Nessas condições, parafraseando Vieira (2013), cada estudante deve encontrar o seu caminho, em diálogo com outros, o que é tão necessário quanto exigente, visto que solicita que o discente se torne descobridor de tais caminhos em detrimento da ação de se tornar seguidor de caminhos. Não se trata, no entanto, de uma ação isolada e de 
natureza contemplativa ou especulativa, mas de uma reflexão comprometida com a formação e a profissão docente e, por isso, da construção e vivência de um processo problematizador e emancipatório.

Neste texto, ao perseguir os sentidos e saberes da experiência, identificados como algo subjetivo, discutimos a experiência do desenvolvimento do Projeto Profissão Docente (PPD), realizado no Instituto Federal de Educação Ciência e Tecnologia do Ceará (IFCE), campus Tianguá. ${ }^{1}$ Este projeto foi criado, em uma perspectiva de investigação e ação crítico-reflexiva, atrelado ao protagonismo estudantil na sua profissionalização. $O$ referido projeto foi desenvolvido nos semestres 2018.2 e 2019.1 e buscamos forjar a formação político-pedagógica, a permanência e o êxito dos estudantes dos cursos de licenciatura em física e letras português/inglês - IFCE/campus Tianguá.

As questões básicas que surgiram no planejamento e desenvolvimento deste projeto foram: quais as condições, nos cursos de licenciaturas em física e letras - português/inglês do IFCE/campus Tianguá pode favorecer a profissionalização docente? Qual o papel das diversas disciplinas das licenciaturas na constituição da profissionalização docente?

Desenvolver o PPD significou, em termos teórico-práticos, para nós, professores formadores, reconhecer a necessidade de uma reflexão sobre a inserção, a permanência e o êxito dos estudantes em cursos de licenciatura. Entretanto, conscientes de que a reflexão por si mesma significaria muito pouco, delineamos algumas ações a serem desenvolvidas visando alicerçar a (trans)formação dos estudantes para a docência.

O propósito deste estudo é duplo: por um lado, evidenciar que, muitas vezes, em tempo paralelo ao trabalho das disciplinas curriculares dos cursos de licenciatura, é possível e desejável aproximar os estudantes de experiências educativas que fortaleçam uma cultura de profissionalização; por outro lado, ilustrar o papel dos estudantes, em diálogo com outros e, em especial, com o contexto das escolas básicas, como construtores do conhecimento sobre e para a sua profissionalização. Não podemos falar de profissionalização docente sem entendê-la, também, como um trabalho discente de autoconstrução e autodescoberta docente. Existe, assim, uma íntima relação entre a profissionalização docente e o protagonismo estudantil nesse mesmo processo.

A profissionalização, como um processo de (trans)formação de um indivíduo para uma determinada profissão, depende, sobretudo, do protagonismo desse mesmo sujeito no referido processo. Como escreveu Gorzoni (2017, p. 1402) “[...], a profissionalização está circunscrita à etapa de formação inicial, que termina com a certificação do aluno e com o reconhecimento de sua competência para exercer a profissão docente". Assim, o argumento que desde logo defendemos é: a profissionalização docente exige dos estudantes tomadas de decisões e opções pedagógicas alicerçadas em uma perspectiva crítico-reflexiva, histórica, social e política, visando sempre a transformar a ordem social vigente.

Neste debate, não discutimos as diferentes concepções sobre o protagonismo estudantil e as estratégias usadas para desenvolvê-lo. ${ }^{2}$ Em vez disso, enfatizamos a ideia de protagonismo

\footnotetext{
${ }^{1}$ No que segue, empregaremos a sigla PPD para indicar o Projeto Profissão Docente (PPD) e IFCE para nos referirmos ao Instituto Federal de Educação, Ciência e Tecnologia do Ceará (IFCE). A expressão IFCE/Campus Tianguá é, aqui, empregada para fazer alusão ao campus do Instituto Federal de Educação, Ciência e Tecnologia do Ceará (IFCE) em Tianguá (CE).

2 A esse respeito, ver: Miorando, Leite (2018); Silva, Andrade (2018); Vitória et al (2018).
} 
estudantil em relação à profissionalização docente. Consideramos, inclusive, que existe ainda pouca ênfase sobre a relação entre protagonismo estudantil e profissionalização docente.

Damos ênfase, assim, à reflexão do protagonismo como uma prática social-políticoreflexiva dos estudantes de assumirem-se como arquitetos da sua profissionalização docente. ${ }^{3}$ Entender os estudantes das licenciaturas como arquitetos da sua profissionalização implica desafiá-los a pensar, (re)criar e (trans)formar-se para a profissão. É nesta perspectiva que entendemos que a profissionalização docente "[...] acontece em comunidades de professores [e estudantes] que se apoiam mutuamente e em que um sustenta o crescimento do outro" (ZEICHNER, 2008, p. 543).

Neste texto, além desta introdução, apresentamos as seguintes seções: inicialmente, situamos o quadro do problema no qual se encontra a discussão e a experiência aqui discutida. Em seguida, uma breve exposição sobre a base teórica do PPD. No que segue, discutimos as principais conclusões e lições apreendidas no contexto da experiência vivida. Por último, apresentamos as reflexões finais e as referências deste estudo.

\section{CONSTRUÇÃO DO PROBLEMA: ADENDO NECESSÁRIO}

A experiência aqui discutida se situa no campo da formação inicial de professores, no Brasil, especificamente no âmbito dos cursos de licenciatura em física e letras - português/inglês do IFCE/campus Tianguá. Como dito na introdução deste estudo, dentre os problemas persistentes na formação inicial dos professores, destacam-se a inserção, a permanência e o êxito dos estudantes em cursos de licenciatura. Nesse âmbito, os índices de evasão e de retenção acadêmica dos últimos dez anos na Rede Federal de Educação Profissional e Tecnológica (Rede Federal) têm sidos significativos e contrariam, de certo modo, a perspectiva de universalização do acesso à educação e da garantia da permanência (VIEIRA, GALLINDO, CRUZ, 2017). ${ }^{4}$

Inclui-se no cenário exposto, necessariamente, os cursos de licenciatura que são ofertados no âmbito da Rede Federal de Educação Profissional e Tecnológica. No caso específico do IFCE/campus Tianguá, são ofertados atualmente dois cursos técnicos - Agricultura e Informática; três superiores, sendo dois cursos de licenciatura - física e letras português/inglês; e um curso de bacharelado em ciência da computação (BRASIL, 2018).

Considerando os dados expostos, as leituras e as investigações que temos feito em torno da formação inicial dos professores, sobretudo com foco na profissionalização docente, na pedagogia, na didática e nos estágios supervisionados, evidenciam um aspecto que nos chama a atenção: a motivação com o curso, alicerçada, sobretudo, em fatores individuais, mas também externos, tem papel fundamental para a permanência e o êxito dos estudantes em cursos de licenciatura e, em consequência, para a qualidade da formação inicial docente.

É no quadro desse pressuposto que retomamos as perguntas de partida do PPD, e aqui já evidenciadas: quais as condições, nos cursos de licenciatura em física e letras - português/inglês do IFCE/campus Tianguá, que podem favorecer a profissionalização docente? Qual o papel das

\footnotetext{
${ }^{3}$ Neste debate, utilizamos o vocábulo arquitetos para realçar o universo de potencialidades que é cada estudante das licenciaturas para criar, transformar e de fazer diferente o trabalho pedagógico. Em uma mesma perspectiva, Vieira (2013) tem defendido amplamente o professor como arquiteto da pedagogia.

${ }^{4}$ No contexto do Plano Estratégico do IFCE, a evasão seria toda e qualquer saída do estudante de seu curso sem êxito (VIEIRA, GALLINDO, CRUZ, 2017). Essa questão pode ser vista e aprofundada no âmbito do Plano Estratégico do IFCE (VIEIRA, GALLINDO, CRUZ, 2017).
} 
diversas disciplinas das licenciaturas na constituição da profissionalização docente? O fato é que, de um modo ou de outro, "[...] estamos perante um momento crucial da história [da profissão e formação] dos professores e da escola pública. Precisamos repensar [...] as nossas instituições e as nossas práticas" (NÓVOA, 2017, p. 1111). Deparamo-nos, assim, com a necessidade de contribuir para a reflexão e a defesa de políticas, teorias, práticas e reflexões epistemológicas de formação de professores capazes de apontar caminhos para a melhoria da formação inicial docente, articulada, necessariamente, à valorização profissional do magistério em suas diferentes feições.

Diante do quadro de evasão e de retenção acadêmica no IFCE, foi elaborado o Plano Estratégico do IFCE ${ }^{5}$, documento que visa assegurar a permanência e o êxito dos estudantes por meio do fortalecimento da qualidade do ensino (VIEIRA, GALLINDO, CRUZ, 2017). Numa perspectiva sumária, destacamos as principais causas da evasão e retenção no IFCE, mais precisamente o ponto 6. do PEI - desmotivação com o curso - (Ponto 7.1 - fatores individuais):

Falta de identificação ou de afinidade com o curso; desconhecimento ou pouco conhecimento sobre o curso escolhido; falta de perspectiva profissional; Imaturidade da própria idade para escolha precoce da profissão; falta de aptidão; descontentamento de alguns estudantes dos cursos integrados que têm interesse em se preparar para o ENEM; desmotivação ocasionada pelas sucessivas repetências; desestímulo pela área de formação; o vínculo ao curso aconteceu por circunstâncias diversas e não por ser uma primeira opção; desmotivação ocasionada em alguns cursos por ser de nível alto; cursos mais teóricos que práticos; dificuldade de aprendizagem nas disciplinas propedêuticas em especial, as de exatas e língua portuguesa; dificuldade de aprendizagem nas disciplinas técnicas; reprovações em disciplinas que são prérequisitos (VIEIRA, GALLINDO, CRUZ, 2017, p. 24).

Os pontos já evidenciados aqui da formação inicial dos professores, em especial o quadro das principais causas da evasão e retenção no IFCE, mais precisamente o ponto 6 . do PEI desmotivação com o curso - (Ponto 7.1 - fatores individuais), nos permitem compreender que é "[...] imprescindível construir modelos que valorizem a preparação, a entrada e o desenvolvimento profissional docente" (NÓVOA, 2017, p. 1113).

A educação brasileira, a profissão e a formação docente no contexto social-político contemporâneo foi o tema do PPD, este que se vinculou ao PEI do IFCE, documento macro, por meio das disciplinas de didática, estágio supervisionado, entre outras. ${ }^{6} \mathrm{O}$ objeto do referido projeto, em regime de colaboração entre as disciplinas acima mencionadas, foi a formação político-pedagógica dos estudantes dos cursos de licenciatura em física e letras português/inglês, por meio de atividades de ensino e pesquisa que se configuraram como apoio à formação e à construção da identidade docente dos estudantes.

Parafraseando Canário (2008) e André (2016), compreendemos que o processo de profissionalização docente exige que os estudantes desenvolvam uma atitude de pesquisador, o que vai exigir a aquisição de habilidades tais como: formular questões a respeito da realidade que

\footnotetext{
${ }^{5}$ Usaremos a sigla PEI para retomar, quando necessário, o Plano Estratégico do IFCE.

6 História da educação; política e gestão educacional; estrutura e funcionamento do ensino; métodos e técnicas de pesquisa educacional; fundamentos sócio-filosóficos da educação.
} 
o cerca, buscar dados e referências para elucidar as questões que o intrigam, saber tratar os dados e referências localizadas e ser capaz de expressar seus achados.

O objetivo que orientou a experiência em discussão foi: desenvolver ações de ensino e pesquisa para o fortalecimento da formação político-pedagógica, permanência e êxito dos estudantes dos cursos de licenciatura em física e letras - português/inglês, IFCE/campus Tianguá.

Em um primeiro momento, buscamos oportunizar aos discentes subsídios teóricos e práticos para o desenvolvimento de iniciativas de pesquisa na educação básica por meio, em especial, dos estágios supervisionados nas escolas públicas - municipais e estaduais - dos munícipios da área de atuação direta do IFCE/campus Tianguá. Afinal, pensamos, como Candau (2016, p. 312), que: “[...] a formação docente deve se dar em parceria entre a universidade e a escola básica: seu centro deve ser a prática profissional”.

Tratou-se do intento de levar os estudantes das licenciaturas a conhecerem da escola básica muito além do que conhecem dela como estudantes que foram outrora, agora com o olhar de docente em formação. Em síntese, como nos ensina Canário (2008, p. 146), é "[...] nas escolas que se aprende a profissão de professor, na medida em que esse processo de aprendizagem se sobrepõe a um processo de socialização profissional."

Considerando a proposta de que os estudantes desenvolvessem uma produção narrativa crítico-reflexiva, procurando narrar (desvelar) os caminhos que os levaram (levam) à docência, como parte constituinte das atividades dos estágios, a dinâmica das atividades teve como suporte um trabalho de reflexão sobre a importância dos relatos autobiográficos na formação dos professores. Nessas atividades, em específico, trabalhamos a partir das contribuições de Cunha (1997) e André (2004), entre outros.

Em um segundo momento, realizamos formações (palestras e mesas-redondas) que oportunizaram a aproximação dos estudantes a problemáticas que perpassam as escolas de educação básica, a profissão e a formação docente no contexto social-político contemporâneo. Procurando, assim, conferir um lugar de maior destaque às escolas de educação básica na formação docente, "[...] fazendo dela[s] um dos principais eixos de formação ao longo do currículo" (VIEIRA, 2013, p. 614). Nessa perspectiva, realizamos o I e II Encontros Pedagógicos Interdisciplinares e I e II Encontros de Práticas de Ensino, Didática e Estágio Supervisionado dos cursos de letras e física do IFCE/campus Tianguá, como atividade constitutiva da organização pedagógica dos referidos cursos, bem como visando socializar as pesquisas e práticas desenvolvidas na educação básica. ${ }^{7}$ Tratou-se, portanto, do desafio de construir a formação docente como um processo pedagógico, complexo, multidisciplinar e espaço entre a relação teórico-prática - das diversas áreas do conhecimento que dialogam e sustentam o ato educativo.

Tais ações tiveram como protagonistas os próprios discentes que, juntamente com os docentes envolvidos e professores convidados de outras instituições, desenvolveram o I e II Encontros Pedagógicos Interdisciplinares e I e II Encontros de Práticas de Ensino, Didática e Estágio Supervisionado dos cursos de letras e física do IFCE/campus Tianguá.

Enfatizar os caminhos percorridos na experiência em tela implica evidenciar também os fatores institucionais - de ordem pedagógica ou administrativa - que influenciam, direta ou

\footnotetext{
${ }^{7}$ Não é nosso objetivo detalhar as atividades acadêmico-científicos-culturais desenvolvidas no âmbito do PPD, pois este estudo não se inscreve como um relatório, mas como um argumento, problematização e abordagem das questões levantadas e possíveis contribuições da experiência vivida à profissionalização dos estudantes das licenciaturas.
} 
indiretamente, o processo de evasão e de retenção dos estudantes no IFCE. Os estudantes, no ponto 5 do PEI - questões didático-pedagógicas - (Ponto 7.2 - fatores internos à instituição), revelaram que:

\begin{abstract}
Muito conteúdo por aula para pouca quantidade de horas de aula semanal, consequentemente, baixo aprendizado e desinteresse; volume excessivo de conteúdos por aula; desmotivação ocasionada pela dificuldade didática de alguns professores. [...]; avaliações de aprendizagem (provas) com conteúdo em excesso; ausência de planejamento de aulas por parte de alguns docentes; utilização de material didático desatualizado; aulas não atrativas; falta de atenção de alguns professores com relação às dificuldades de aprendizagem dos estudantes inclusive daqueles com necessidades educacionais específicas; alguns professores demonstram desmotivaşão em ensinar, pois demonstram pouco empenho em ministrar boa aula; dificuldade de comunicação entre professores, alunos e coordenações; falta de domínio de conteúdo de alguns professores; priorização do "repasse" e cumprimento do conteúdo programático em detrimento da aprendizagem [...] (VIEIRA, GALLINDO, CRUZ, 2017, p. $27-$ 28 , grifos nossos).
\end{abstract}

Embora o quadro evidenciado pelos estudantes faça referência ao contexto do IFCE como um todo, aqui nos interessa discuti-lo no âmbito da docência nos cursos de licenciatura.

Precisamos reconhecer que as experiências docentes são únicas e diversificadas e que todas são igualmente importantes quando se trata da profissionalização docente. Assim sendo, não existe uma única prática pedagógica correta ou mais transformadora; existem múltiplas práticas pedagógicas eficazes que podem atender às diferentes realidades encontradas. Conforme nos ensina Vieira (2013), precisamos (re)descobrir caminhos, em diálogo com os estudantes e outros professores, visando aprofundar a reflexão e a (re)criação das nossas práticas. Isso significa que "[...] o processo de compreensão e de melhoria de seu próprio ensino deve começar da reflexão sobre sua própria experiência [...]” docente (ZEICHNER, 2008, p. 539).

Não é objetivo deste debate discutir a docência universitária, porém queremos sublinhar que os estudos de André e Almeida (2017) apontam que há iniciativas para se obter melhores resultados nas práticas formativas docentes. Entretanto, essas ocorrem principalmente no âmbito individual ou a partir de parcerias compostas por dois ou três professores que lecionam em disciplinas afins, ou que partilham de objetivos comuns. Ainda segundo André e Almeida (2017, p. 2017), os professores entrevistados por eles relatam dificuldades em articular interesses e promover relação entre as disciplinas; referem-se às dificuldades do trabalho coletivo, da prática interdisciplinar e relatam que as iniciativas ainda são incipientes. Ao que parece, a falta de diálogo entre as disciplinas e a cultura institucional impulsionam os docentes a trabalharem isoladamente.

É importante considerar, ainda, que, de um modo ou de outro, a desmotivação é elemento que tem perpassado, também, a docência no contexto do IFCE e com claras evidências nos depoimentos dos estudantes. Estamos diante de um quadro, muitas vezes, no qual os professores formadores precisam convencer a si e aos estudantes a permanecerem no magistério.

Assim, a par de todo o cenário até aqui exposto, o PPD buscou possibilitar momentos de aprendizagem e envolvimento contínuo dos estudantes com a profissão docente. Parafraseando Vieira (2013), ousamos dizer que o caminho de mudança tomado no PPD foi um percurso difícil e relativamente marginal, mas também necessário e desejável, haja vista a premente necessidade de imputarmos aos estudantes o aprendizado da docência. 


\section{RESULTADOS E LIÇÕES APREENDIDAS}

Discutir as condições que nos cursos de licenciatura podem favorecer a profissionalização docente exige reconhecer que:

Poucas universidades brasileiras têm uma política definida em relação à formação de professores para o ensino fundamental e médio. Há um desinteresse geral dos Institutos e Faculdades pelas licenciaturas. Com isso, os professores saem despreparados para o exercício da profissão, com um nível de cultura geral e de informação extremamente baixo, o que resulta num segmento de profissionais sem as competências pessoais e profissionais para enfrentar as mudanças gerais que estão ocorrendo na sociedade contemporânea. Do ponto de vista do sistema de ensino, as propostas de intervenção em nível federal têm sido, ainda, bastante modestas, porque não tratam a questão no seu conjunto (LIBÂNEO, 2007, p. 43-44, grifos nossos).

Nesse âmbito, sublinhamos também uma cultura acadêmica radicada, em muitas Instituições de Ensino Superior (IES), de desvinculação entre o ensino e a pesquisa, visão tecnicista do professor e a naturalização de um cenário de priorização do ensino, bem como o cumprimento da carga horária docente, em sala de aula, em detrimento de atividades de pesquisa, eventos acadêmico-científicos-culturais, dentre outras atividades pedagógicas. Usamos itálico em ensino visando destacar que é um fato inegável que nem sempre a ação de ensinar se configura, predominantemente, como um ato político-intencional que se desdobra em aprendizagem.

Ao longo dos anos, temos acompanhado pelas diferentes IES onde exercemos a docência, e à medida que nos aprofundamos na literatura do campo da formação docente, modos habituais de desvalorização da investigação pedagógica e a falta de condições e apoio institucional, em especial, pedagógico, no tocante à docência no ensino superior. Em muitos casos, temos assistido que "[...] aos professores, permite-se apenas que ajustem os meios para se atingir objetivos definidos por outras pessoas. $O$ ensino torna-se meramente uma atividade técnica" (ZEICHNER, 2008, p. 542). Esse processo desdobra-se, por um lado, na desprofissionalização docente e, por outro, no isolamento profissional dos professores formadores no âmbito das licenciaturas. Do ponto de vista de Libâneo (2007, p. 43-44), isso faz emergir o:

[...] abandono da sala de aula em busca de outro trabalho, redução da procura dos cursos de licenciatura, escolha de cursos de licenciatura ou pedagogia como última opção (em muitos casos, são alunos que obtiveram classificação mais baixa no vestibular), falta de motivação dos alunos matriculados para continuar o curso (grifos nossos).

De um modo ou de outro, a falta de motivação dos alunos matriculados para continuar o curso parece ser o elemento subjacente aos acontecimentos que antecederam a elaboração do PPD, as experiências vividas e, agora, discutidas. Isto é, continuamos a nos defrontar com a necessidade de colocar o trabalho pedagógico das diversas disciplinas dos cursos de licenciatura a serviço da profissionalização docente. Trata-se da necessidade de compreendermos que "[...] acolher os estudantes das licenciaturas e torná-los professores, capazes de se integrarem na profissão e contribuírem para a sua renovação [...]" (NÓVOA, 2017, p. 1114) exige, por um lado, relações didático-pedagógicas das diversas disciplinas, como discutiremos nos próximos 
parágrafos, e, por outro lado, atividades pedagógicas que fortaleçam a experiência educativa de sala de aula.

Primeira lição apreendida: faz-se necessário forjar uma cultura pedagógica fortemente associada a essa profissionalização. Isso significou, em termos teórico-práticos, para nós professores formadores, construir um equilíbrio sábio entre o vivido-construído em sala de aula, em cada disciplina, e a efetivação de atividades coletivas (PPD) para o fortalecimento da profissionalização docente. Assim como exigiu-nos assumir que a nossa condição de formadores reclama um protagonismo docente-pedagógico que, de certo modo, vai além da ação em sala de aula e, por isso, ousamos (re)descobrir caminhos. Não podemos deixar de destacar que o protagonismo docente, de certo modo, além da ação em sala de aula:

[...] não signifique demandas excessivas de tempo, energia e expertise, desviando a atenção deles [professores] de sua missão central com os estudantes. [Pois,] em alguns casos, ao se criar mais oportunidades para os professores participarem na tomada de decisões, no âmbito [...] [dos cursos de licenciatura], sobre o currículo, [...], o ensino etc., isso pode significar a intensificação de seu trabalho, fazendo com que se torne ainda mais difícil para eles desempenharem a tarefa primordial de formação de seus estudantes (ZEICHNER, 2008, p. 541-542).

Somos conscientes, entretanto, de que "[...] aqueles que decidem explorar novos caminhos terão de se esforçar muito mais e estarão sujeitos a mais críticas, exatamente porque o seu trabalho é marginal e questiona valores e práticas dominantes" (VIEIRA, 2013, p. 153).

Consideramos, ainda, que forjar uma cultura pedagógica fortemente associada à profissionalização docente, sobretudo no contexto educacional brasileiro, exigiu-nos defender uma pedagogia para a autonomia discente-docente, reconhecendo-os como arquitetos da pedagogia, não só no que diz respeito à ação em sala de aula (VIEIRA, 2013). ${ }^{8}$ Da nossa perspectiva, isso significou provocar mudanças e movimentos de protagonismo estudantil na sua profissionalização. ${ }^{9}$ De certo modo, buscamos, discentes-docentes, no contexto do PPD, nos assumirmos como arquitetos da pedagogia e fomos desenhando as ideias, concretizando as ações e ajustando-as em função da reflexão-ação que construíamos, vivenciando uma verdadeira práxis pedagógica.

Bem próxima a essa persistência, queremos retomar mais uma questão, mas, aqui, reformulada: qual o papel das disciplinas de formação pedagógica em face, muitas vezes, de uma cultura acadêmica de não condições à profissionalização docente?

Do nosso ponto de vista, uma consequência dessa indagação está na nossa segunda lição apreendida: fomentar a constituição de comunidades - discentes e docentes - para o estudo e a construção de um trabalho, para além do que já ocorre dentro da sala de aula, visando à melhoria da formação docente nos cursos de licenciatura.

\footnotetext{
${ }^{8}$ Esse entendimento de discente como arquitetos da pedagogia remete-nos ao protagonismo dos estudantes Remes Freire, Jacione dos Santos, Wallisy Medeiros, Gabriel Rodrigues, Thiago Melo nas atividades do PPD. A esses mesmos alunos, nossos agradecimentos. Igualmente, agradecemos ao prof. Jackson Nunes e Vasconcelos, Clemilton Ferreira, Ariane Sales, Carlos Walkyson Silva e Katiana de Paula pela colaboração no desenvolvimento das atividades da experiência discutida neste texto.

${ }^{9}$ A mudança sobre a qual aqui se fala é uma mudança profunda em uma perspectiva de afetar. Afetar, conforme nos ensinam Cruz e André (2014), como a ação de mobilizar e aproximar, neste caso, da docência.
} 
Desse modo, as diversas disciplinas dos cursos de licenciatura podem favorecer a emergência de um movimento, a priori, de indagação crítica, individual e, também, coletivo, centrado na profissionalização docente. Posteriormente, podem vir a fomentar a construção de espaços coletivos, para além das salas de aula, que fortaleçam predominantemente o visto-vivido, individualmente, em cada disciplina. Trata-se da construção de um trabalho para além do que já ocorre dentro da sala de aula, entre quatro paredes, em cada disciplina. Pensamos, inclusive, pautados nas contribuições de Shulman (2014), que se trata da constituição de comunidades discentes e docentes - para o estudo e a melhoria da formação nos cursos de licenciatura.

Pensar sobre a construção de espaços coletivos de profissionalização docente para além das salas de aula implica, necessariamente, entendermos que as chamadas disciplinas específicas não podem se isolar desse cenário. Isto é, a problematização das questões da formação inicial de professores, as quais têm, por certo, implicações na permanência e êxito dos estudantes nos cursos de licenciatura, não pode ficar sob a responsabilidade apenas das chamadas disciplinas de formação pedagógica. Por outro lado, as disciplinas específicas não podem envolver-se apenas genericamente em questões atinentes à profissionalização docente.

O divórcio, muitas vezes, entre as disciplinas de formação pedagógica e as disciplinas específicas não é novidade no campo da formação docente no Brasil. Assim, constitui-se um desafio corrente no contexto das licenciaturas pensar em um trabalho dessa natureza: constituição de comunidades - discentes e docentes - para o estudo e a construção de um trabalho para além do que já ocorre dentro da sala de aula, visando à melhoria da formação nos cursos de licenciatura. Além do mais, um trabalho dessa magnitude depende, em parte, do poder transformador da reflexão profissional individual, mas também coletiva e, sobretudo, da concepção de educação, de docência e da (re)valorização da pedagogia no meio acadêmico (VIEIRA, 2013). As decisões, opções pedagógicas e como nós, professores formadores, incorporamos uma postura crítico-reflexiva aos fatores institucionais e sociais que condicionam a nossa ação são imprescindíveis nesse processo.

Nesse cenário, reconhecemos o importante lugar do PPD como um espaço de diálogo entre as disciplinas de formação pedagógica e, timidamente, com as disciplinas específicas. Por outras palavras, destacamos a colaboração da experiência em questão na disseminação de práticas coletivas que, em tempo paralelo ao trabalho docente nas salas de aulas, buscou garantir experiências teórico-práticas radicadas a uma perspectiva coletiva e interdisciplinar. Como dito acima, procuramos, também, não deixar as disciplinas específicas à margem desse processo.

Uma terceira questão bastante relacionada à profissionalização docente é: qual o papel das diversas disciplinas dos cursos de licenciatura na constituição da profissionalização docente? No rastro dessa questão, situamos a terceira lição apreendida: construir inter-relações didático-pedagógicas - entre as diversas disciplinas dos cursos de licenciatura - com vistas à constituição da profissionalização docente.

O sentido de inter-relações didático-pedagógicas entre as diversas disciplinas dos cursos de licenciatura que aqui nos interessa tem a ver com a construção de espaços coletivos para a edificação do conhecimento capazes de implicar a permanência e êxito dos estudantes. Isto é, empregamos a expressão inter-relações didático-pedagógicas entre as disciplinas como a "[...] construção de um espaço e de um tempo onde seja possível trabalhar em comum” (NÓVOA, 2017, p. 11, grifos do autor).

Precisamos reconhecer que não têm existido, muitas vezes, diálogos didático-pedagógicas entre as diversas disciplinas e, por vezes, nem as condições necessárias no âmbito de muitas IES. Consideramos, assim como apontam André e Almeida (2017), que essa questão é atual e urgente, pois as práticas dos professores formadores que, por sua vez, são muito afetadas pelas condições 
de trabalho em seu contexto institucional, têm também o papel fundamental na permanência e no êxito dos estudantes nos cursos de licenciatura e, futuramente, na qualidade do ensino da escola básica.

Uma questão que podemos colocar é: que condições são necessárias para que essa interrelação didático-pedagógica entre as disciplinas se concretize?

É importante considerar que está cada vez mais claro que a formação dos professores exige práticas formativas que ocorram, principalmente, no âmbito coletivo em detrimento do individual. Por outras palavras, não só teremos de construir melhores práticas, no âmbito individual, mas elevarmos nosso trabalho coletivo. Teremos, assim, de construir, em diálogo com outros, processos de inter-relações didático-pedagógicas centrados na profissionalização docente.

É nessas inter-relações didático-pedagógicas das diversas disciplinas que reside, em parte, o segredo da profissionalização docente e, por isso, da construção de processos que alicerçam a permanência e o êxito dos estudantes nos cursos de licenciatura. Enquanto a profissionalização docente, o ensinar a ensinar nos cursos de licenciatura, não se constituir objeto em todas as disciplinas, a permanência e o êxito dos estudantes nos cursos de licenciatura serão apenas um ideal e, portanto, o contributo para a melhoria da formação docente não ficará evidente nem ao nível individual ou local.

Consideramos, então, que inter-relações didático-pedagógicas entre as diversas disciplinas dos cursos de licenciatura proporcionam ganhos inestimáveis à profissionalização dos estudantes e, possivelmente, serão lembradas como práticas dos bons professores. Continuamos, no entanto, a ter muita dificuldade em reconhecer que a profissionalização docente se forja, de certo modo, "[...] com certa parcela de contribuição, com base nas práticas didáticas de professores que se destacam em qualidade comparativamente a outros" (CRUZ; MARCEL, 2014, p. 61). ${ }^{10}$ Trata-se de reconhecermos "[...] o papel que os professores mais capazes podem e devem assumir junto dos jovens [...] [futuros professores]" (NÓVOA, 2017, p. 1124). Em síntese, "[...] a ação docente do professor formador constitui um eixo central na formação do conhecimento profissional básico do futuro professor" (ANDRÉ; ALMEIDA, 2017, p. 204).

Ao abordarmos, nesta seção, os principais resultados e lições apreendidas, buscamos ensaiar possíveis caminhos para a suplantação, ou pelo menos dirimir, sobretudo, os fatores internos à instituição, questões didático-pedagógicas com implicações na evasão e retenção dos estudantes no IFCE. ${ }^{11}$ Em contrapartida, argumentamos que iniciativas para a obtenção de melhores resultados na formação dos estudantes, futuros profissionais do magistério, em especial do sistema nacional de educação básica, precisam ocorrer não somente no âmbito individual, mas, em especial, coletivo.

\section{REFLEXÕES FINAIS}

Este estudo discutiu alguns dos desafios enfrentados na formação inicial dos professores, mas especificamente para a permanência e o êxito dos estudantes nos cursos de licenciatura, tendo como terreno a experiência do Projeto Profissão Docente desenvolvido no IFCE/campus Tianguá.

10 Diz respeito ao argumento de que “[...] as práticas dos formadores referenciais promovem aprendizagens significativas" (CRUZ; MARCEL, 2014, p. 80).

${ }^{11}$ Ver: Ponto 7.2 do Plano Estratégico para Permanência e Êxito dos Estudantes do IFCE (2017- 2024). 
Os principais resultados e lições apreendidas, como os achados da experiência vivida, permitiram-nos visualizar que foi possível: mobilizar para fazer junto aos estudantes, uma análise crítica da educação, da profissão e da formação docente no contexto social-político-econômico e cultural contemporâneo; alargar o repertório cultural dos estudantes, à medida que fomentamos o seu protagonismo na própria profissionalização e, em especial, embora de modo relativamente tímido, articular interesses e promover a integração das disciplinas por meio de um trabalho coletivo.

Nesse sentido, as disciplinas de formação pedagógica, de certo modo, cumpriram seu papel ao buscar constituir uma comunidade - discentes e docentes - para o estudo e a construção de um trabalho para além do que já ocorria dentro da sala de aula, visando à melhoria da formação nos cursos de licenciatura.

Sobre os desdobramentos do quadro de questões que subsidiaram a efetivação do PPD, é possível constatar que elas nos obrigaram a reconhecer a necessidade do fortalecimento da indissociabilidade entre o ensino, a pesquisa e a extensão nos cursos de licenciatura. Essa exigência corresponde, de certo modo, ao argumento, neste debate, da necessidade de ações coletivas - discentes - docentes - de intervenção e monitoramento para superação do quadro de evasão e retenção no IFCE.

Tudo isso nos faz concluir que é urgente a necessidade de inter-relações didáticopedagógicas entre as diversas disciplinas dos cursos de licenciatura com vistas à profissionalização docente. Entretanto, reconhecemos que a construção dessas inter-relações didático-pedagógicas é ainda um caminho difícil e relativamente pouco explorado no âmbito de muitas IES, mas necessário e desejável se quisermos que a permanência e o êxito dos estudantes nos cursos de licenciatura constituam-se como uma realidade. Assim, o PPD, conduzido nesses moldes, perseguiu o intento de pensar, recriar e (trans)formar para a profissão docente e, desse modo, contribuiu para o desafio de mobilizar ou, quem sabe, (re)aproximar discentes e docentes da docência como opção profissional.

\section{REFERÊNCIAS}

ANDRÉ, Marli. Memorial, instrumento de investigação sobre o processo de constituição da identidade docente. Contrapontos - v. 4, n. 2, p. 283-292 - Itajaí, maio/ago. 2004. Disponível em https://bityli.com/KhITo. Acesso em $1^{\circ}$ maio. 2019.

ANDRÉ, Marli Eliza Dalmazo Afonso de. A Formação do Pesquisador da Prática Pedagógica. Plurais Revista Multidisciplinar, v. 1, n. 1, p.30-41, jan./abr. 2016. Disponível em https://bityli.com/d67kh. Acesso em 14 nov. 2018.

ANDRÉ, Marli Eliza Dalmazo Afonso de; ALMEIDA, Patrícia Cristina Albieri de. A profissionalidade do professor formador das licenciaturas. Rev. educ. PUC-Camp., Campinas, 22(2):203-219, maio/ago., 2017. Disponível em https://bityli.com/iKdR3. Acesso em 21 jun. 2019.

BRASIL, Ministério da Educação. Instituto Federal de Educação, Ciência e Tecnologia do Ceará, Campus Tianguá. Projeto Pedagógico do Curso (PPC) de Licenciatura em Física, 2013.

BRASIL, Ministério da Educação. Secretaria de Educação Profissional e Tecnológica. Instituto Federal do Ceará, Campus Tianguá. Projeto Pedagógico do Curso de Licenciatura Superior de licenciatura em física (Noturno), 2018. 
CANDAU, Vera Maria. Ensinar - aprender: desafios atuais da profissão docente. Revista COCAR, Belém, Edição Especial n. 2, p. 298-318 - ago./dez. 2016. Disponível em https://bit.ly/38UMAxv. Acesso em 24 jan. 2020.

CANÁRIO, Rui. Formação e desenvolvimento profissional dos professores. In: PORTUGAL. Ministério da Educação. Direção Geral dos Recursos Humanos da Educação (org.). Presidência Portuguesa do Conselho da União Europeia: desenvolvimento profissional de professores para a qualidade e para a equidade da aprendizagem ao longo da vida. Lisboa: Ministério da Educação, 2008. p. 131-148.

CUNHA, Maria. Isabel. Conta-me agora! As narrativas pedagógicas na pesquisa e no ensino. Revista da Faculdade de Educação, São Paulo, v. 23, n. 1. p. 149-184, jan./dez., 1997. Disponível em https://bityli.com/wQyLe. Acesso em 28 jun. 2018.

CRUZ, Giseli Barreto da; ANDRÉ, Marli Eliza Dalmazo Afonso de. Ensino de Didática: um estudo sobre concepções e práticas de professores formadores. Educação em Revista, Belo Horizonte, v. 30, n. 4, p. 181-203, out./-dez., 2014. Disponível em https://bityli.com/ZKBTi. Acesso em 28 jun. 2019.

GORZONI, Ś́lvia de Paula; DAVIS, Claudia. O Conceito de profissionalidade docente nos estudos mais recentes. Cadernos de Pesquisa, v. 47, n. 166, p. 1396-1413, out./dez., 2017. Disponível em https://bityli.com/uUzWB. Acesso em 1º mar. 2019.

LIBÂNEO, José Carlos. Adeus professor, adeus professora? Novas exigências educacionais e profissão docente. $10^{\mathrm{a} e d, ~ S a ̃ o ~ P a u l o, ~ C o r t e z ~ E d i t o r a, ~} 2007$.

MIORANDO, Bernardo Sfredo; LEITE, Denise. Dimensões do engajamento estudantil para o contexto brasileiro: a emergência política da participação para a inovação pedagógica na Educação Superior. Educação Por Escrito, Porto Alegre, v. 9, n. 2, p. 173-190, jul./dez., 2018. Disponível em https://bityli.com/fpf5J. Acesso em $1^{\circ}$ fev. 2019.

NÓVOA, António. Firmar a posição como professor, afirmar a profissão docente. Cadernos de Pesquisa, v. 47, n. 166, p. 1106-1133, out./dez., 2017. Disponível em https://bityli.com/kPZrv. Acesso em 18 jun. 2017.

SILVA, Adan Renê Pereira da; ANDRADE, Anne Karina Pereira de. Formação docente e protagonismo estudantil de acadêmicos de Medicina: desafios e perspectivas. Educação Por Escrito, Porto Alegre, v. 9, n. 2, p. 191-206, jul./dez., 2018. Disponível em https://bityli.com/cOWNB. Acesso em $1^{\circ}$ fev. 2019.

SHULMAN, Lee. Conhecimento e ensino: fundamentos para a nova reforma. Cadernos Cenpec, São Paulo, v.4, n.2, p.196-229, dez. 2014. Disponível em https://bityli.com/Foc8t. Acesso em 9 maio 2018.

VIEIRA, Armênia Chaves Fernandes; GALLINDO, Erica de Lima; CRUZ, Almeida Hobson. Plano estratégico para permanência e êxito dos estudantes do IFCE. Fortaleza: IFCE, 2017. Disponível em https://bityli.com/BhjTe. Acesso em 1 ${ }^{\circ}$ jul. 2019.

VIEIRA, Flávia. O professor como arquiteto da pedagogia na universidade. Revista Teias, v. 14, n. 33, p. 138-156, 2013: Dossiê Especial. Disponível em https://bityli.com/TROxt. Acesso em $1^{\circ}$ jul. 2019.

VITÓRIA, Maria Inês Côrte et al. Engajamento acadêmico: desafios para a permanência do estudante na Educação Superior. Educação (Porto Alegre), v. 41, n. 2, p. 262-269, maio/ago. 2018. Disponível em https://bityli.com/78pmd. Acesso em 01 fev. 2019. 
ZEICHNER, Kenneth M. Uma análise crítica sobre a "reflexão" como conceito estruturante na formação docente. Educ. Soc., Campinas, v. 29, n. 103, p. 535-554, maio/ago. 2008. Disponível em https://bityli.com/Qj8EM. Acesso em 1º jul. 2019.

Submetido em junho de 2020 Aprovado em outubro de 2020

\section{Informações do(a)(s) autor(a)(es)}

Osmar Hélio Alves Araújo

Universidade Federal da Paraíba (UFPB)/Campus IV

osmarhelio@hotmail.com

ORCID: https://orcid.org/0000-0003-3396-8205

Link Lattes: http://lattes.cnpq.br/0422935292610713

Dayana Silva de Oliveira

Instituto Federal de Educação, Ciência e Tecnologia do Ceará (IFCE) - Campus Quixadá

dayana.oliveira@ifce.edu.br

ORCID: https://orcid.org/0000-0002-5369-5454

Link Lattes: http://lattes.cnpq.br/0818872750494337

* Agradecimentos, afetuosamente, ao prof. Dr. Emerson Augusto de Medeiros e a profa. Dra. Silmara de Oliveira Gomes Papi pelas contribuições na versão preliminar do presente texto. 